\title{
Developments in Ophthalmology
}

Vol. 13

Series Editor

W. Straub, Marburg a. d. Lahn 


\section{Complications in Modern Ophthalmic Surgery}

Volume Editor

I. Strempel, Marburg a. d. Lahn

90 figures, 2 color plates and 23 tables, 1987 


\section{Contents}

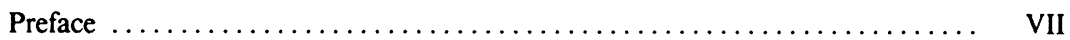

Acknowledgements $\ldots \ldots \ldots \ldots \ldots \ldots \ldots \ldots \ldots \ldots \ldots \ldots \ldots \ldots \ldots \ldots \ldots \ldots \ldots$ VII

Wolfgang Straub 65 Years. Congratulations to Prof. Dr. med. Dr. med. h.c. Wolfgang Straub by Martin Reim (Aachen) $\ldots \ldots \ldots \ldots \ldots \ldots \ldots$ IX

Reim, M.; Qinkler, G. (Aachen): Complications of Lid Surgery ........... 1

Severin, M.; Kirchhof, B.; Hartmann, C. (Köln): Diffuse Epithelial Ingrowth after

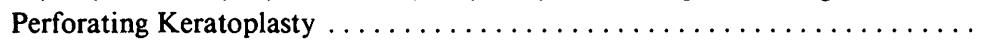

Aust, W.; Wernhard, U. (Kassel) Defects of Descemet's Membrane as a Complication in Cataract Extraction with Lens Implantation ...........

Draeger, J.; Winter, R. (Hamburg): The Corneal Endothelium as a Standard for the

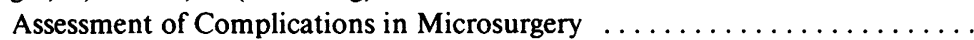

Costa, G. (Rio de Janeiro): Complications in Posterior Chamber Lens Implanta-

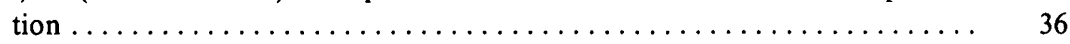

Domarus, D. von; Burk, R.; Sievers, H. (Hamburg/Kiel): Tissue Changes Induced by Intraocular Lenses. A Histopathologic Study (with 1 color plate).........

Schũtte, E.; Pötzsch, D.; Schiefer, U. (Ulm): Combined Cataract-Glaucoma Operation and Its Complications with 7-S-Intraocular Lens (with 1 color plate)

Neubauer, H.; Kirchhof, B.; Arnold, G. (Köln): Complications after Modern Filter

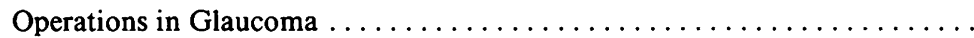

Weder, W.; Lissel, U.; Stöltzing, M. (Marburg a. d. Lahn): Complications and

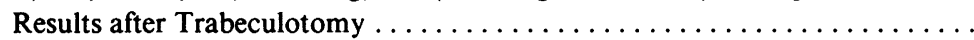

Demeler, U. (Bremen): Direct Cyclopexy after Persistent Hypotony as a Complication after Cyclodialysis and Goniotomy $\ldots \ldots \ldots \ldots \ldots \ldots \ldots \ldots$

Lemmen, K.-D.; Dimopoulos, S.; Kirchhof, B.; Heimann, K. (Köln): Keratopathy Following Pars plana Vitrectomy with Silicone Oil Filling ............

Kreissig, I. (Tübingen): The Balloon-Gas-Procedure. Another Move towards

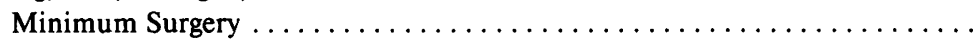

Wiegand, W. (Marburg a. d. Lahn): Complications of Retinal Xenon-Arc Photo-

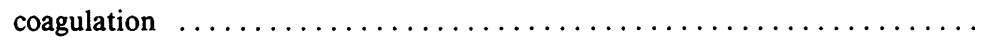

Kaufmann, H. (Giessen): Complications in Eye Muscle Surgery ............

Welge-Lüssen, L.; Schroeder, H.G.; Glanz, H. (Frankfurt/Marburg a. d. Lahn): Complications in Orbital Lesions $\ldots \ldots \ldots \ldots \ldots \ldots \ldots \ldots \ldots \ldots$

Schmidt, B.; Berghaus, A. (Berlin): Complications in Frontal Defects . . . . . . . 125 
Strempel, I. (Marburg a. d. Lahn): Complications by Liquid Plastics in Ophthalmic

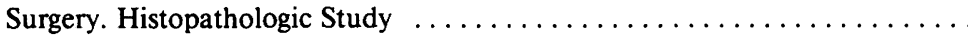
Beiter, G.; Lerche, W.; Oberhauser, M. (Wiesbaden): Occlusion of a Branch of the Central Retinal Artery by a Corpus alienum as a Rare Complication of the Carotid Arteriography

Rossmann, H. (Hamburg): Legal and Actuarial Technical Questions in Intraocular Complications

Subject Index 
Dev. Ophthal., vol. 13, pp. 125-136 (Karger, Basel 1987)

\title{
Complications of Frontal Defects
}

Immobilization of the Eye

\author{
B. Schmidt ${ }^{\mathrm{a}}$, A. Berghaus ${ }^{\mathrm{b}}$

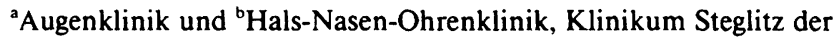 \\ Freien Universität Berlin
}

In the preantibiotic era, there were occurrences of uncontrolled sinusitis that broke into the orbit and led to vision impairment and severe illness [Sariban and Freyens, 1979]. We are reporting on a patient (I.K.), born January 12,1932, who developed an orbital phlegmon in 1946. With considerable organizational difficulties, it was possible at that time to provide her with one of the first antibiotic therapies. At the terminal stage, there was a change in the osseous orbit as well as the eye motility.

Frontal sinus operations were performed in 1949 and 1952; a mucocele of the left frontal sinus was removed in 1980.

The patient presented in the ENT Department of Steglitz Medical Center in 1982. A part of the left frontal bone and the roof of the orbit were missing; the left eye was directed upwards and hardly movable (fig. 1). Of utmost importance to the patient at that time, aside from her desire for correction of the defective eye position, was apparently cosmetic revision of the conspicuous frontal defect with involvement of the orbital margin.

We decided to offer the patient a new type of defect treatment with porous polyethylene [Berghaus, 1985]. Experimental studies have shown that the material is not resorbed and can easily be adjusted as required by virtue of its thermoplastic properties. The implant suitable for an individual case is formed from the patient's face with the aid of a plaster cast.

Porous polyethylene (PHDPE) has a pore size of about $150 \mu \mathrm{m}$ (fig. 2). It is known that the pore system is usually completely filled up with bone within a few weeks after implantation [Klawitter et al., 1976; Spector et al., 1976; Berghaus et al., 1984]. Stable implant anchorage is thus achieved (fig. 3).

For surgical access, we chose a bitemporal incision behind the hairline, which leaves no visible scars. The defect can be easily demonstrated from 


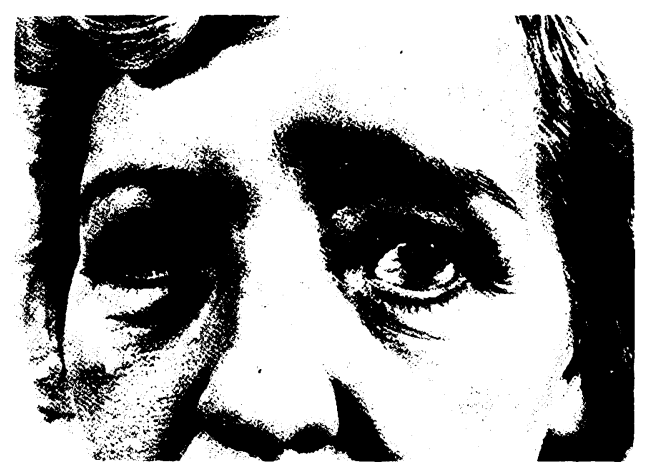

Fig. 1. Patient's face when she presented in 1982. The frontal sinus and the roof of the orbit are missing. The left eye is higher.

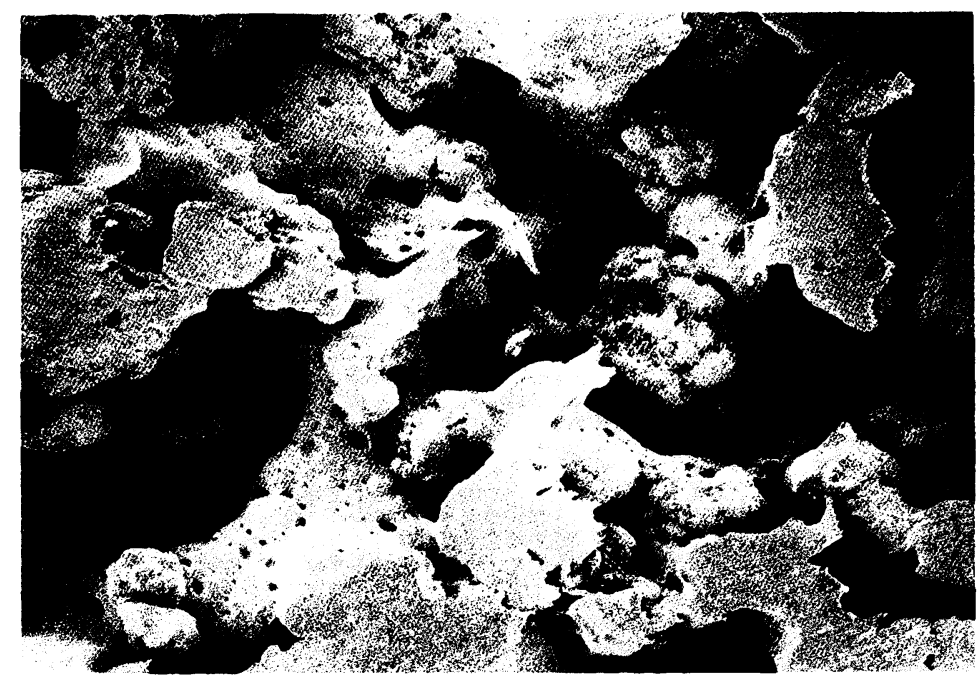

Fig. 2. Cut surface of porous polyethylene. Open pore system. SEM $\times 500$.

here. Care must be taken not to reopen the infundibulum of the frontal sinus towards the nose. In this case, we first filled the defective cavity with bone fragments from the iliac crest (fig. 4) and then covered the orbital margin area with a profile plate of porous polyethylene formed on the plaster cast of the patient's face (fig. 5,6). Having had further good results with this synthetic material in the meantime, we now use it to fill up the entire cavity 


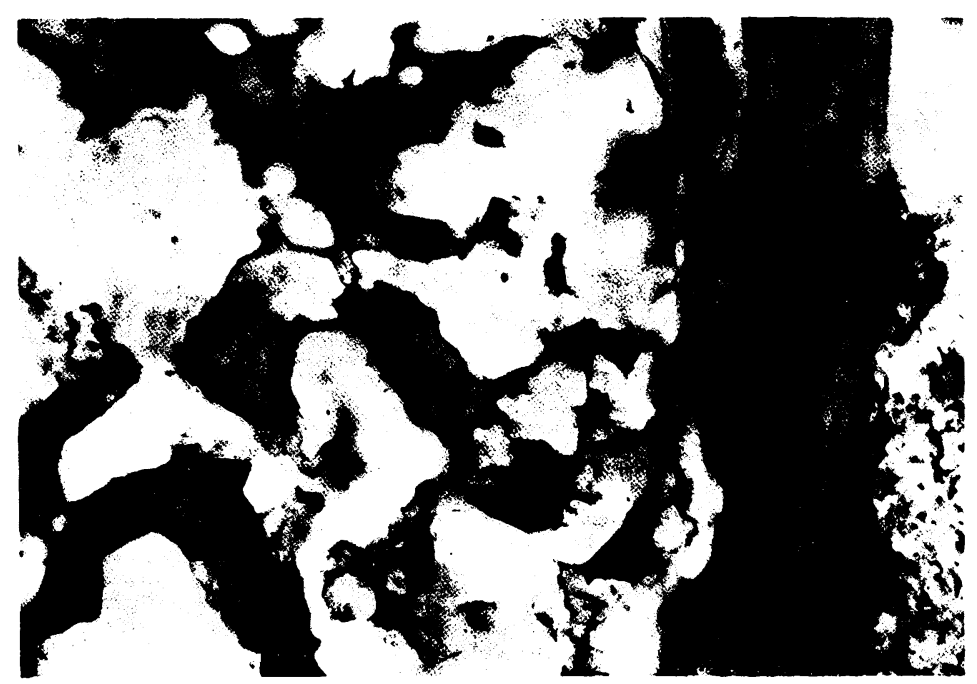

Fig. 3. Growth of bone into the pores of PHDPE 6 weeks after implantation in the calotte of the guinea pig. Giemsa. $\times 180$.

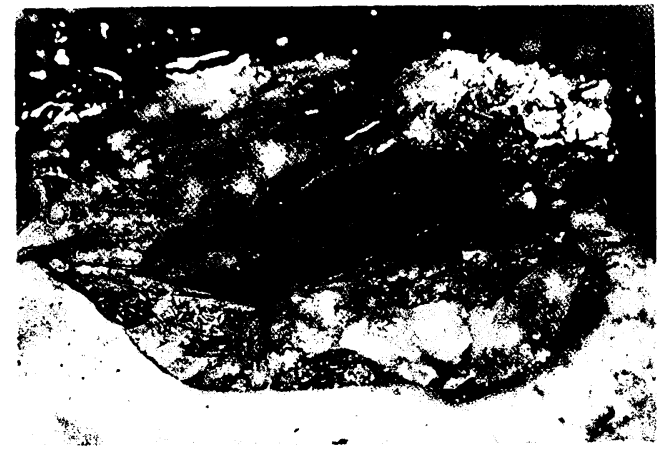

Fig. 4. The frontal defect filled up with bone fragments from the iliac crest.

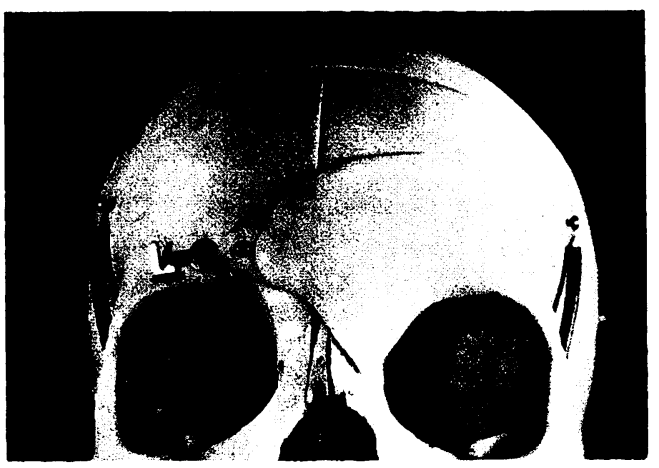

Fig. 5. A profile plate of porous polyethylene for correction of frontal defects. 


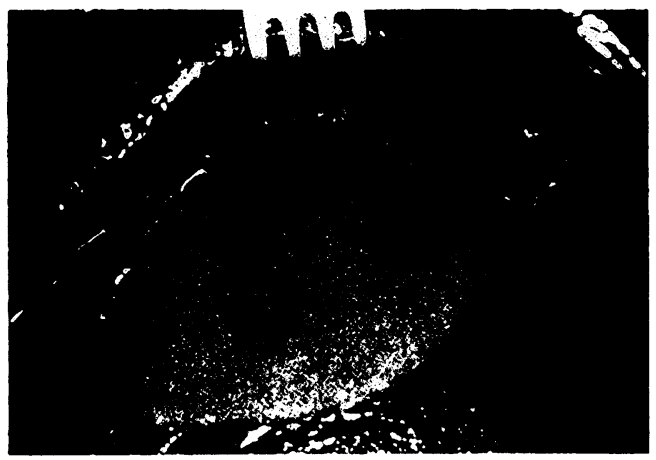

Fig. 6. Profile plate intraoperatively.

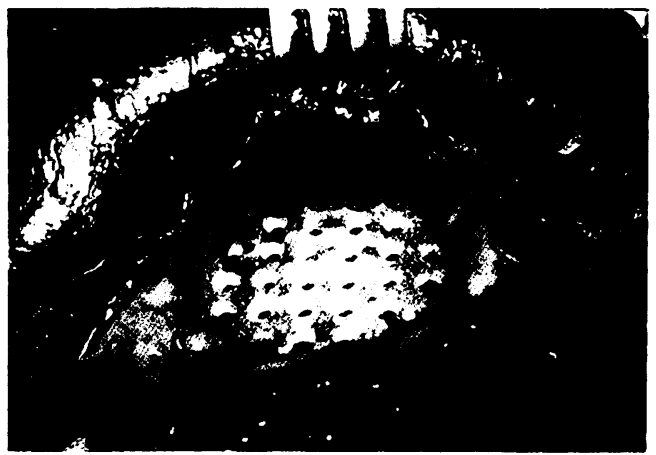

Fig. 7. Filling of a frontal defect with a perforated PHDPE block.
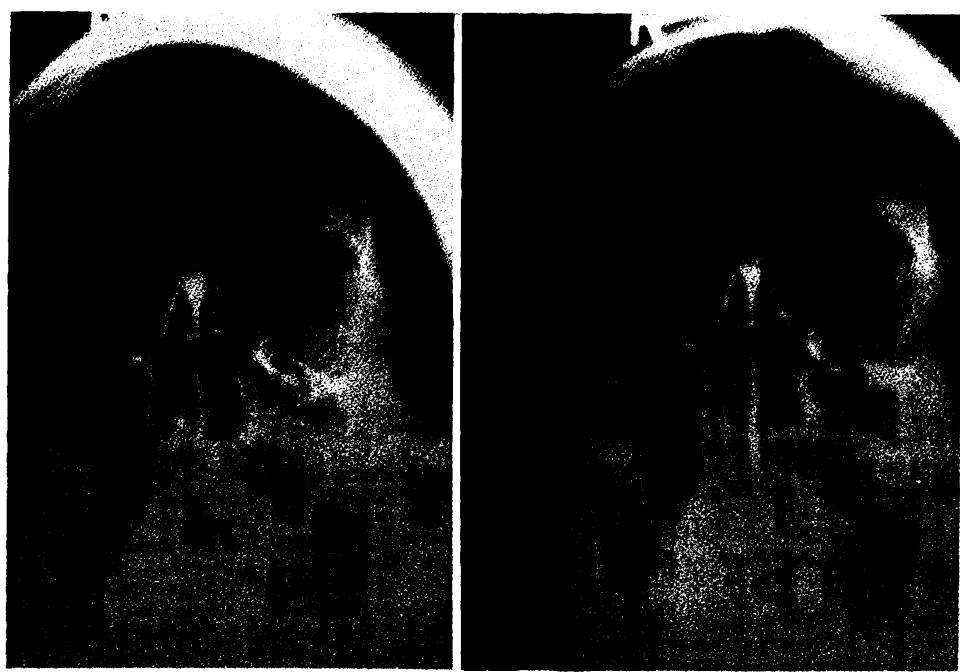

Fig. 8. X-ray before (left) and 1 year after correction of the frontal defect with iliac crest bone and a profile plate of porous polyethylene (right). Ossification of the defect area. 
in such cases (fig. 7). The material permits smooth and symmetrical contouring of the forehead. The postoperative course has been normal up to the present time. The result of the intervention was and has remained satisfactory. Radiological comparison preoperatively and 1 year postoperatively shows the expected ossification of the former large defect cavity after filling with iliac crest bone (fig. 8). Even 3 years postoperatively, the cosmetic result remained essentially unaltered (see fig. 14).

After reconstruction of the forehead and the roof of the orbit, the patient underwent cosmetic and functional restoration of the eye position. The left eye was in divergence: far $9^{\circ}$, near $17^{\circ}$ with a negative vertical divergence: far $14^{\circ}$, near $17.5^{\circ}$. A lowering of the left eye was not possible (fig. 9a). With no signs of irritation in the right eye, the left eye evidenced a narrow pupil with posterior synechia, apparently as the result of an old intraocular inflammation in connection with the orbital phlegmon. A diplopia examination on the tangent scale was not possible, since the axes of the eyes were outside the measuring range. Vision: $+3.25-1.25 / 100^{\circ}=1.2$, right eye; $+3.15-1.0 / 90^{\circ}$, left eye.

In the first operation, wide adhesions of Tenon's capsule and the sarcolemmas were divided. Circumscribed areas of scar tissue were noticed. The musculus rectus superior was freed, and the conspicuously thin musculus rectus inferior was likewise rid of cicatricial funiculi and slightly antepositioned.

The following squint angle was found postoperatively: far: D $10-$ VD $6^{\circ}$; near: D 17 - VD $10^{\circ}$.

On the whole, there was freeer motility. With fixation on the right, it was then also possible to perform a tangent-scale test according to Harms (fig. 10a) as well as a synoptometric examination (fig. 11). Binocular vision was even restored with a prism correction. At first, there was still suppression for the left eye, but binocular vision for far and near was possible after further exercise.

A further operation was performed half a year later. The now stronger rectus inferior was resected by $3 \mathrm{~mm}$, likewise the rectus internus.

After this operation, binocular vision could be achieved without prisms. The Bagolini test was positive for far and near. The squint angle was as follows: far: $\mathrm{C} 1^{\circ}+\mathrm{VD} 1^{\circ}$; near: $\mathrm{C} 5^{\circ}+\mathrm{VD} 1-2^{\circ}$. There was a fusion angle of $10^{\circ}$ in adduction and $3^{\circ}$ in abduction; $5^{\circ}$ in the verticals. There was now a small binocular visual field (fig. 13a); the double-image scheme (fig. 10b) and the synoptometric findings (fig. 12) of course still showed a residual angle in the secondary positions. 

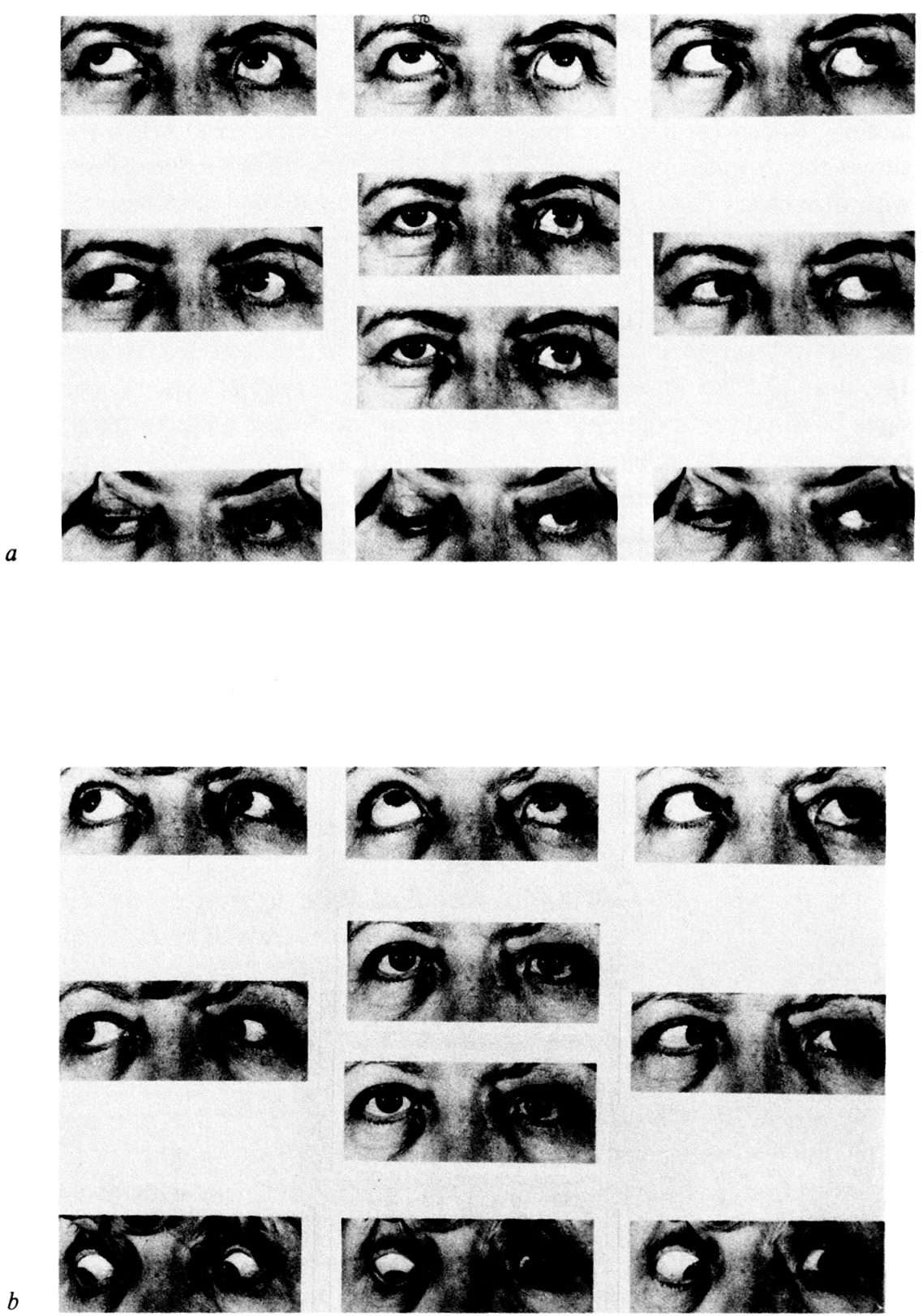

Fig. 9. $a$ Picture in nine visual lines. The left eye is higher and can hardly be moved, particularly not lowered. $b$ After Tenon and muscle surgery, the eyes are parallel for the primary position, but a movement deficit is still evident in deorsumduction to the left. 
Fixation by right eye (red glass right)

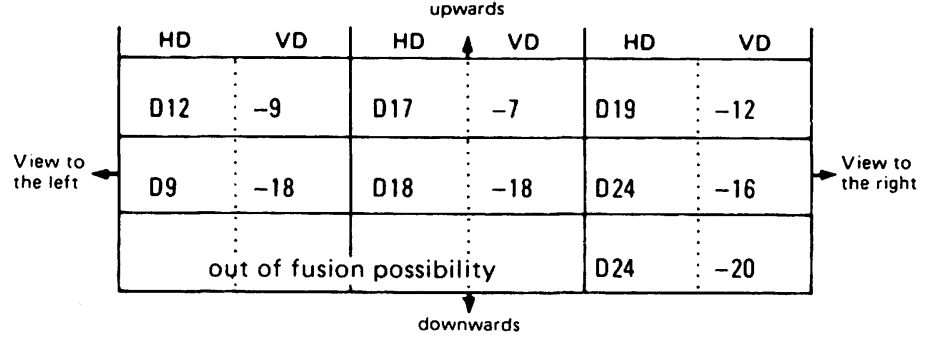

Fixation by left eye (red glass left)

upwards

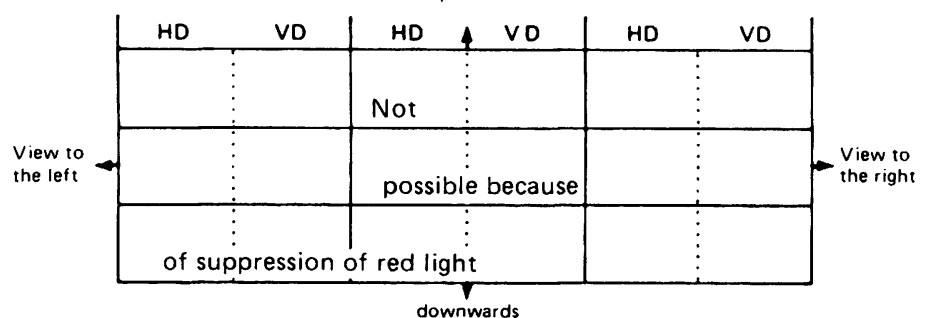

Fixation by right eye (red glass right)

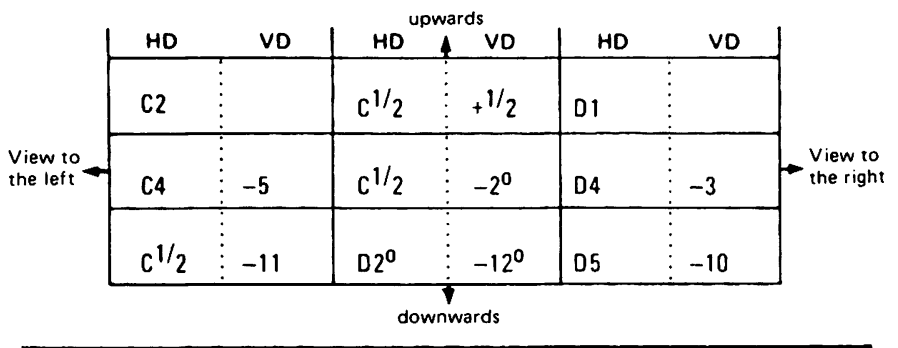

Fixation by left eye (red glass left)

upwards

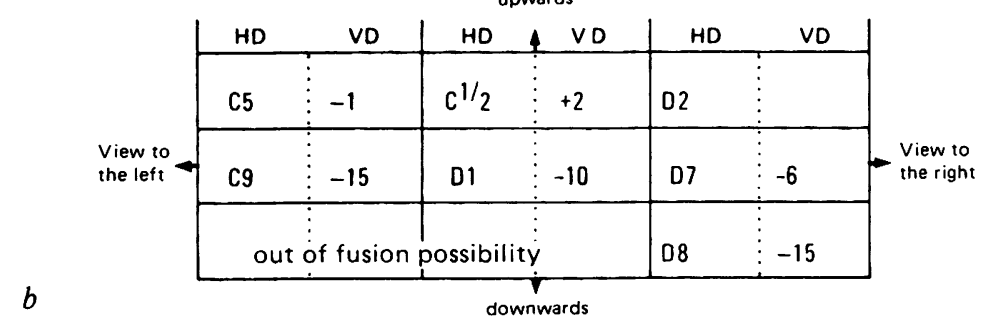

Fig. 10. Tangent scale according to Harms. $a$ The squint angle can be measured with right fixation after the first operation. The double image lies outside the tangent with left fixation. $b$ After the 2 nd operation in primary position and upward binocular vision. 

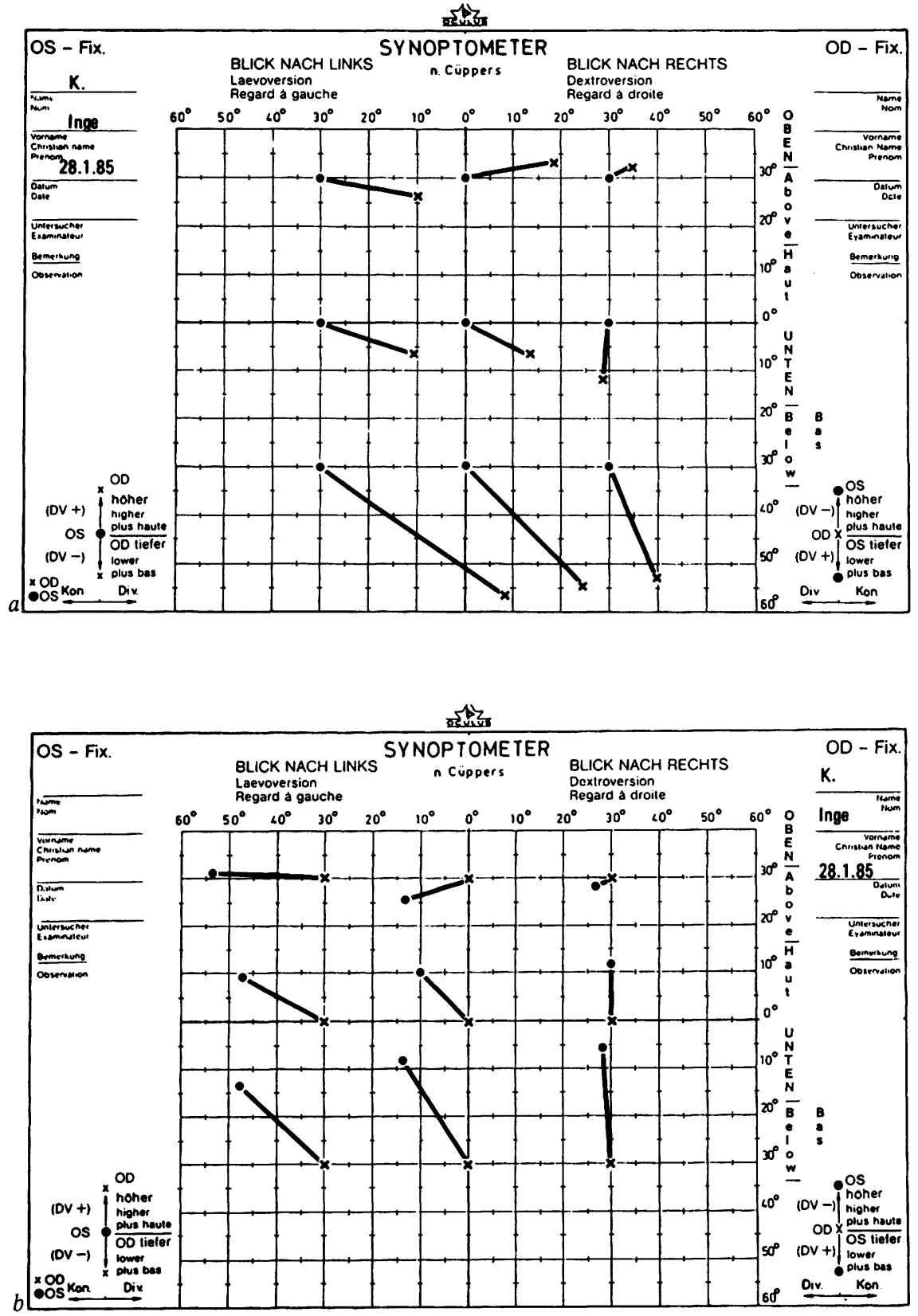

Fig. 11. Synoptometric findings with right $(a)$ and left $(b)$ fixation after the first operation. Considerable movement deficits.. 
舒
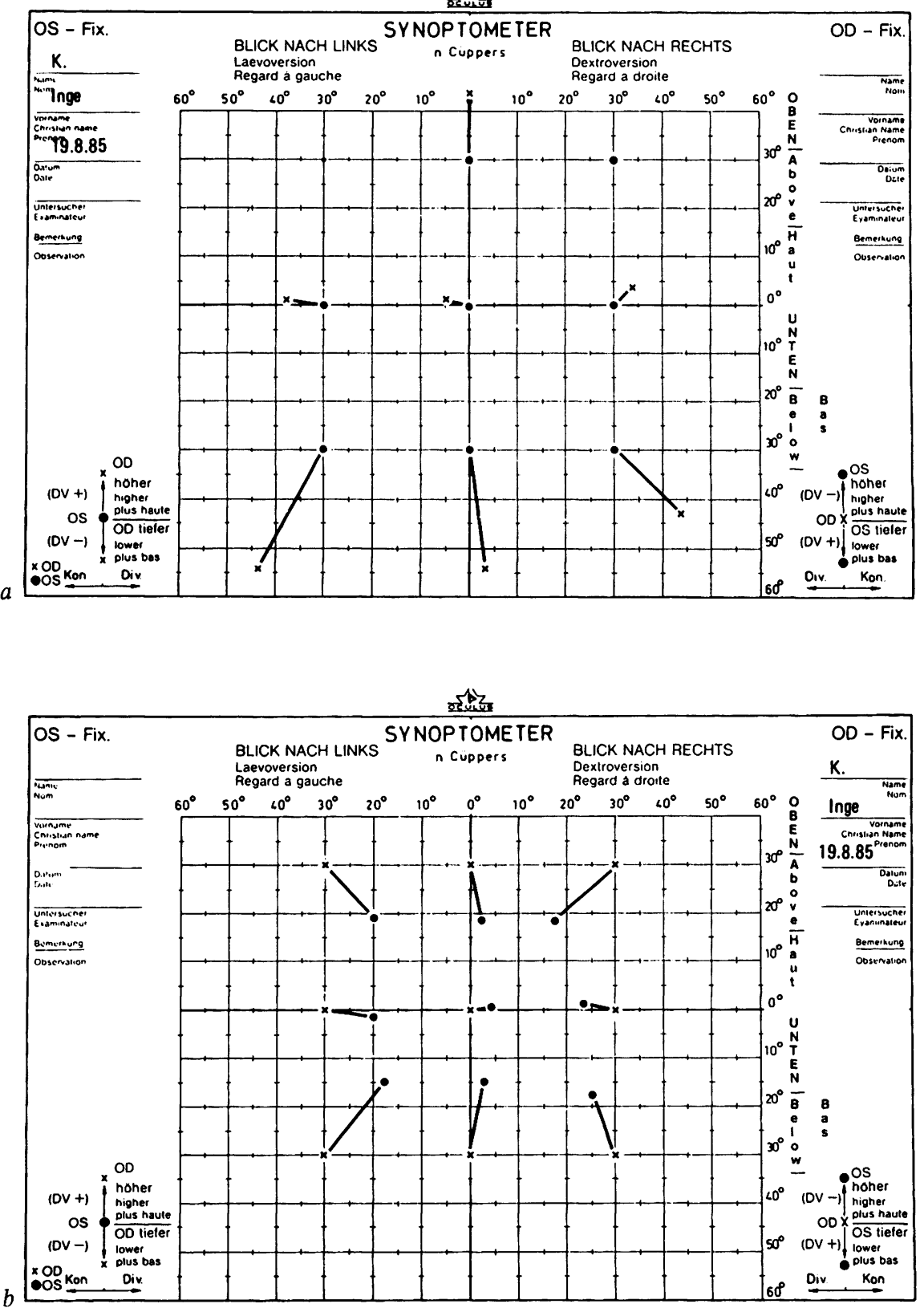

Fig. 12. Only a slight movement deficit still remains in the primary position after the second operation. 

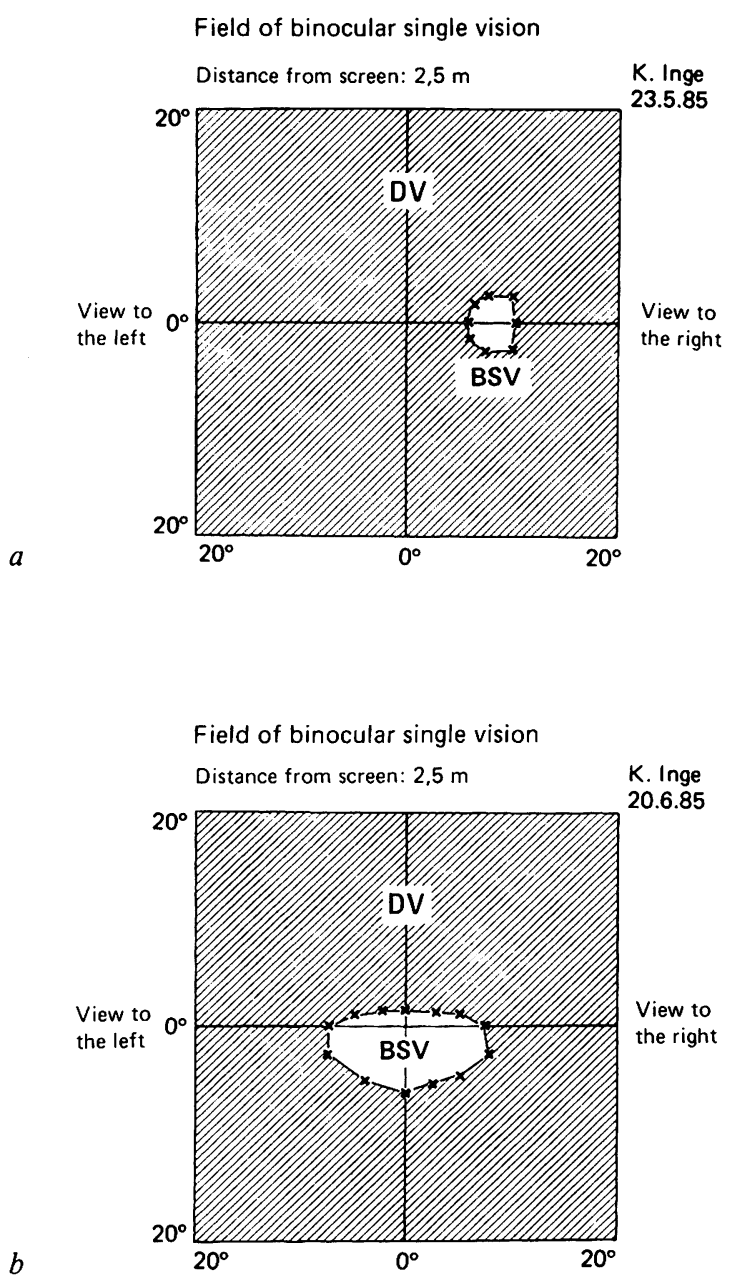

Fig. 13. $a$ At first, there is only a small binocular visual field. $b$ A quarter of a year after the last operation, the binocular visual field has become much larger.

The final result was complete visual acuity on both sides. Right eye still normal; unaltered narrow pupil in left eye. Vision: 1.2 on the right; 1.0 on the left. The squint angle is: C $4-\mathrm{VD} 1^{\circ}$; fusion range $36^{\circ}$ in adduction and $6^{\circ}$ in abduction; synoptometric (fig. 12) and tangent-scale examinations (fig. 10b) show only slight divergence in primary position. The greatest difference is still evident in deorsumduction to the left (fig. 12). The binocular 


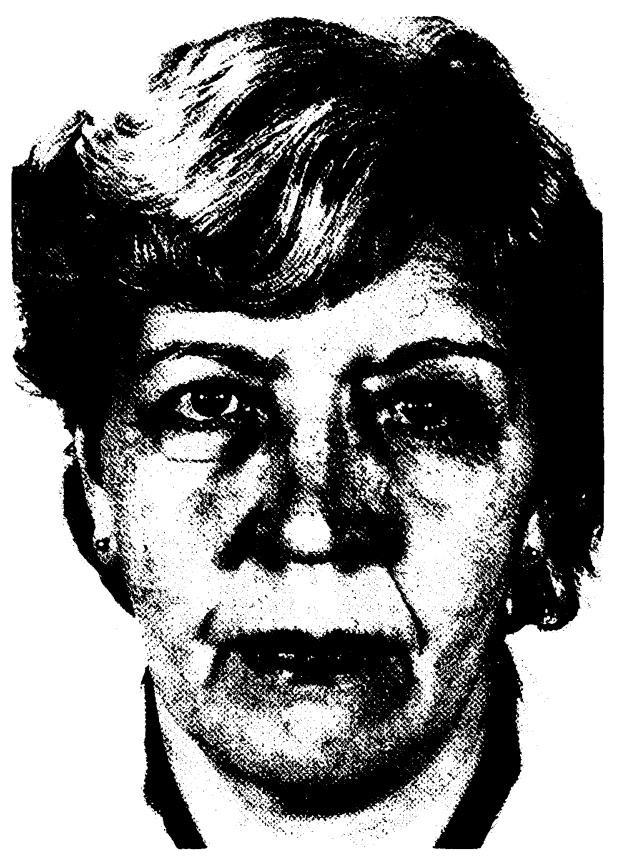

Fig. 14. Patient I.K. 3.5 years after frontal bone surgery and three-quarters of a year after completion of reconstructive eye surgery. The forehead and roof of the orbit are normal. The light reflexes in the eyes are straight.

visual field was now also increased (fig. 13b). There is no forced head posture. Of course, the motility of the left eye is limited, particularly in deorsumduction (fig. 9b). There was slight enophthalmus of the left eye; Hertel difference: $2 \mathrm{~mm}$.

\section{Summary}

A case where the severe course of an orbital phlegmon led to a functionally and cosmetically poor condition is presented. Thirty-five years later, it was possible to achieve a satisfactory result through several operations performed with interdisciplinary cooperation. The orbit and forehead were reconstructed with porous polyethylene, thus ensuring a cosmetically good result. In two operations, the left eye was freed from its upward fixation through cicatrectomy and mobilization of the mucles, so that the eyes were straight again in the primary position. There is a limited binocular visual field. Binocular vision could be restored again after an interruption of 35 years. 


\section{References}

Berghaus, A.: Porous polyethylene in reconstructive head and neck surgery. Archs Otolar. 111: 154-160 (1985).

Berghaus, A.; Mulch, G.; Handrock, M.: Porous polyethylene and proplast. Their behaviour in a bony implant bed. Archs Oto-Rhino-Lar. 240: 115-123 (1984).

Klawitter, J.J.; Bagwell, J.G.; Weinstein, S.M.; Sauer, B.W.; Pruitt, J.R.: An evaluation of bone growth into porous high density polyethylene. J. biomed. Mater. Res. 10: $311-323$ (1976).

Sariban, E.; Freyens, P.: Les atteintes orbitaires des sinusites aigües chez l'enfant. Acta otorhino-lar, belg. 33: 927-935 (1979).

Spector, M.; Flemming, W.R.; Kreutner, A.: Bone growth into porous high-density polyethylene. J. biomed. Mater. Res. 7: 595-603 (1976).

Prof. Dr. Barbara Schmidt, Augenklinik, Klinikum Steglitz der Freien Universität Berlin, Hindenburgdamm 30, D-1000 Berlin 45 